\title{
Gradient heat flux measurement as monitoring tool for the diesel engine
}

\author{
Vladimir Mityakov ${ }^{1}$, Andrey Mityakov ${ }^{1}$, Artem Vintsarevich $^{1, *}$, and Daniil Gerasimov ${ }^{1}$ \\ ${ }^{1}$ Peter the Great St. Petersburg Polytechnic University, Polytechnicheskaya 29, St. Petersburg, 195251, \\ Russian Federation
}

\begin{abstract}
The usage of gradient heat flux measurement for monitoring of heat flux on combustion chamber surface and optimization of diesel work process is proposed. Heterogeneous gradient heat flux sensors can be used at various regimes for an appreciable length of time. Fuel injection timing is set by the position of the maximum point on the angular heat flux diagram however, the value itself of the heat flux may not be considered. The development of such an approach can be productive for remote monitoring of work processes in the cylinders of high-power marine engines.
\end{abstract}

\section{Introduction}

The understanding of the heat exchange in the combustion chamber is key in improving engine efficiency. The rapid changes in gas temperature, pressure and velocity field contribute to its complexity resulting in a highly transient and spatial nature of the heat flux.

Heat transfer measurements inside the combustion chamber pose a challenge in instrumentation due to the harsh environment. At present time heat flux is measured by heat flux sensors based on thermocouples and resistance thermometer. In some cases, pressure sensors are used to calculate gas temperature which in turn is needed to estimate heat flux [15]. However, current types of heat flux sensors cannot measure heat flux directly, also they have response time equal to time of working cycle but for accurate measuring response time should be several times less $[6,7]$.

In this work heterogeneous gradient heat flux sensors (HGHFS) are implemented at different locations in the combustion chamber. The spatially measured heat flux database is a valuable contribution to existing literature.

The first experiments of gradient heat flux measurement carried out in 1996 [8], were of a pioneer nature, but of little practical importance: sensors based on bismuth are inoperable above $200 \ldots 250^{\circ} \mathrm{C}$. Approbation of gradient heat flux sensors is shown in [8-11].

The principle of HGFFS work is based on transversal Seebeck effect. HGHFS allow direct measurement of heat flux with extraordinary response time of $10^{-8} \ldots 10^{-9} \mathrm{~s}$. Heat flux is determined as follows:

$$
q=\frac{e}{S_{0} F}
$$

\footnotetext{
* Corresponding author: vincarevich@yandex.ru
} 
where $q$ is heat flux $\left(\mathrm{W} / \mathrm{m}^{2}\right), e$ is signal of HGHFS $(\mathrm{mV}), S_{0}$ is sensitivity of sensor $(\mathrm{mV} / \mathrm{W}), F$ is area of sensor $\left(\mathrm{m}^{2}\right)$.

\section{Methods}

\subsection{Apparatus}

The research was conducted on Indenor XL4D, four-cylinder, four-stroke, water cooled, divided chamber, medium-high speed diesel engine of automobile duty. The engine has total displacement volume of $1.357 \mathrm{~cm}^{3}$, a cylinder bore of $78 \mathrm{~mm}$, a piston stroke of $71 \mathrm{~mm}$, a compression ratio of 23 , maximum power of $35 \mathrm{~kW}$ at 5000 revolutions per minute (rpm), maximum torque of $84.3 \mathrm{~N} \cdot \mathrm{m}$ at $2500 \mathrm{rpm}$.

Figure 1 shows draw of the measurement system. The first piece is optical TDC marker. Marker outputs square pulse with a dip during peak phase in order to achieve precise detection of top dead center (TDC).

The second piece are heat flux sensors made of nickel-steel composition. Such material allows to use HGHFS in aggressive ambient of combustion chamber for a long time. Sensors have dimensions of $4 \times 4 \times 0,2 \mathrm{~mm}$. Thus size of sensors allows to consider HGHFS do not distort temperature field [8].

The data registration was performed by National Instruments measurement complex. The virtual instrument was built in LabVIEW. For measuring PXI-6289 multifunction module via terminal block TB-2706 was used. Signals were recorded with resolution of $1^{\circ}$ of crankshaft angle.
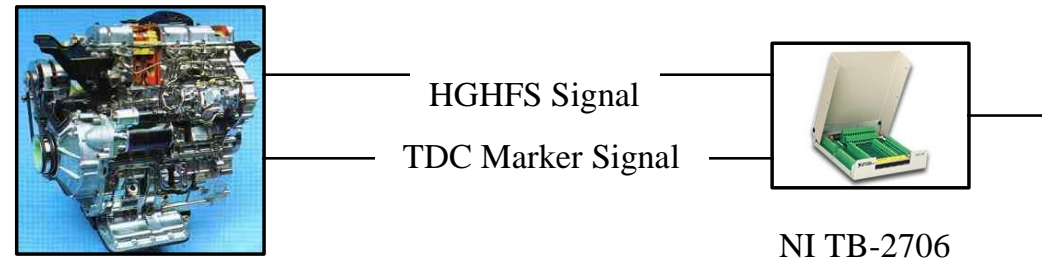

Engine
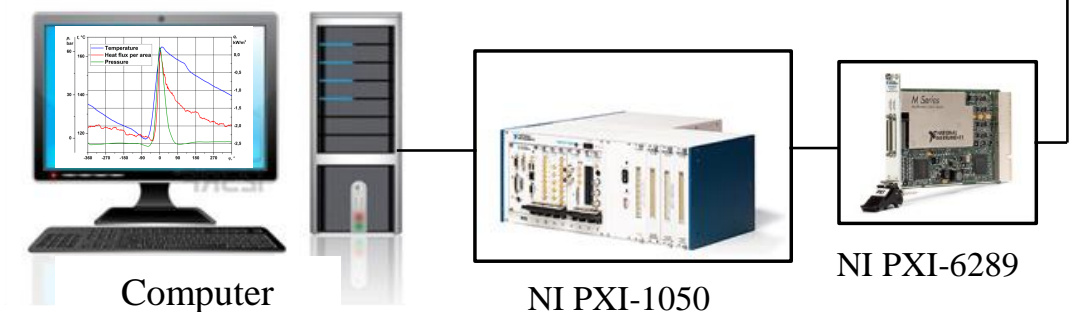

Figure 1. Measurement system diagram.

\subsection{Calibration of heat flux sensor}

HGHFS must be calibrated before measurement. For this purpose, the calibration system was built. Figure 2a shows the schematics of calibration test cell. The calibration was realised according to Joule heating at different temperatures. In this case, an axial electric heater in a cylindrical tube generates a heat flux for the Joule-lanterns, and the HGHFS fixes the heat 


\section{EECE-2018}

flux. Figure $2 b$ shows calibration curve of sensor based on nickel-steel composition. The relative uncertainty was $7.6 \%$.

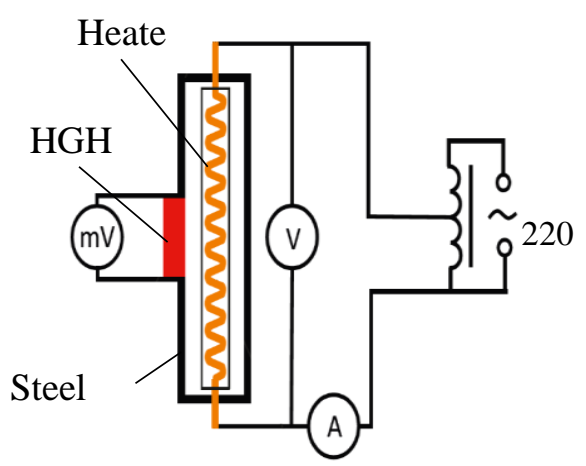

(a)

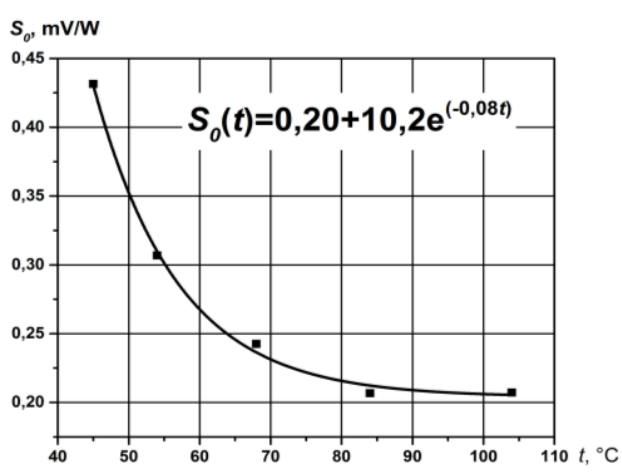

(b)

Figure 2a and Figure 2b. Schematics of calibration system, sensitivity versus sensor temperature.

\subsection{Installation of sensors}

Pilot series of experiments were conducted with HGHFS installed on the cylinder head's wall by probe. Figure 3 shows the schematics of probe and installation of single HGHFS. Sensor was mounted flush with surface of cylinder head.

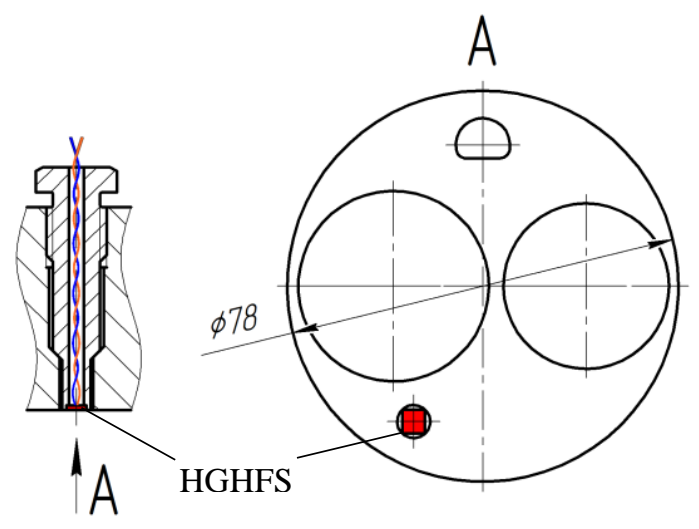

Figure 3. Installation of sensor for pilot experiments.

In the second stage of research four HGHFS were mounted on cylinder head wall as it shown on Figure 4. Wire assemblies were lead out through the service opening used in the first part of the experiment. 

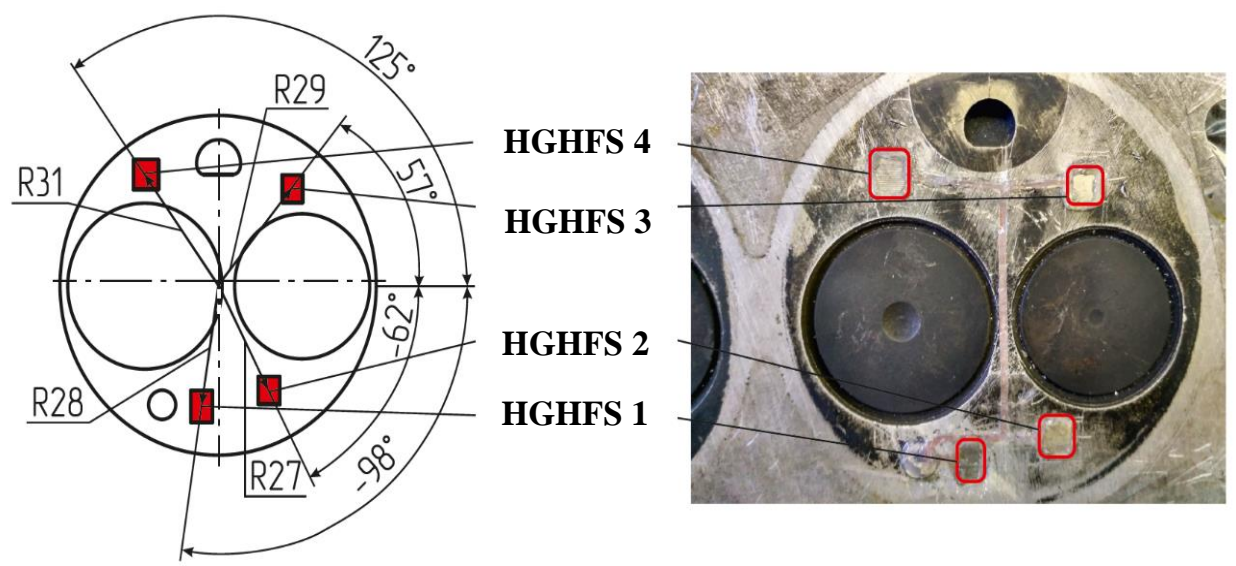

Figure 4. Installation of sensors for second stage.

\section{Results and discussion}

In this work instantaneous heat flux was measured for two different regimes: motored and fire operation. The engine speed was $1500 \mathrm{rpm}$. The measurements were conducted with no load.

Figure 5 shows experimental diagrams for pressure, temperature and instantaneous heat flux, concerning motored operation. It can be seen that the maximum of heat flux is near "hot" TDC [2] and occurs earlier than maximum of wall temperature [12-17]. One can observe that closing of inlet valve near $180^{\circ}$ before TDC and opening of exhaust valve near $180^{\circ}$ after TDC affect the instantaneous heat flux. In the first case heat flux sharply decrease. In the second one it can be noted moderate increasing.

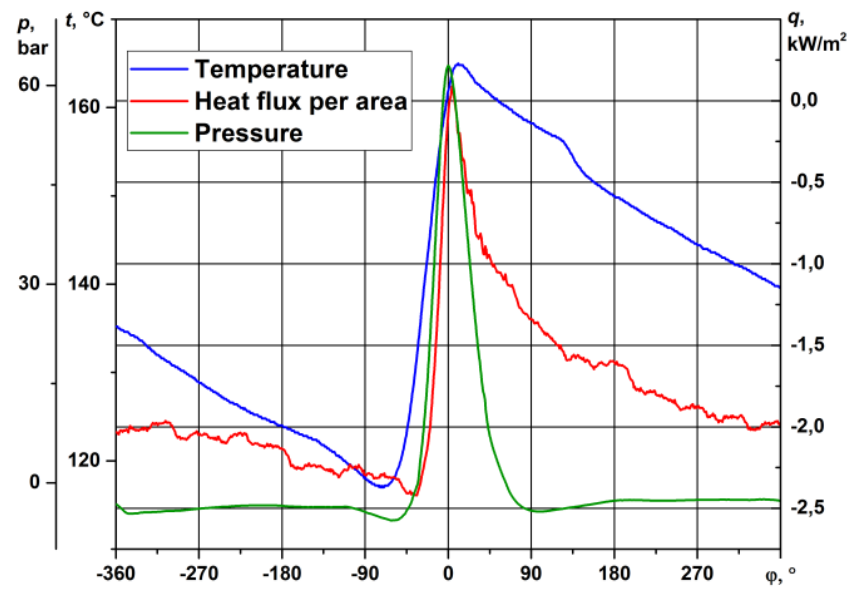

Figure 5. Instantaneous heat flux, pressure indicator diagram and wall temperature for motored operation at $1500 \mathrm{rpm}$.

Figure 6 shows corresponding changes of instantaneous heat flux and advance injection angle (AIA). It can be observed that deviation from default injection angle leads to reducing of heat flux value. Also maximum of heat flux drifts further from TDC. A decrease of injection angle by $18^{\circ}$ leads to shifting of maximum of heat flux by $60^{\circ}$ and reducing its value by $20 \%[18-20]$. 
During operation with late injection angle it can be seen sharp fall of heat flux near TDC. It is caused by heat consumption of fuel for evaporation.

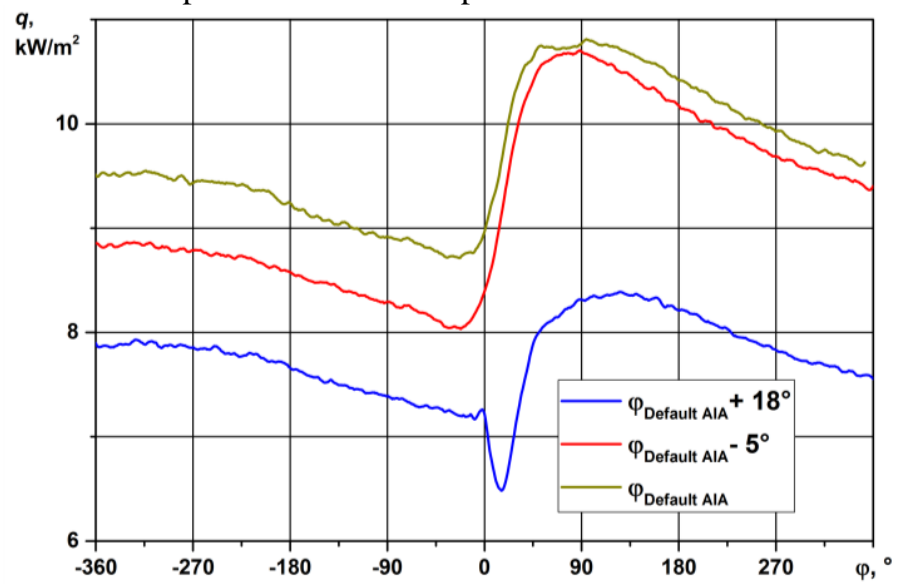

Figure 6. Variation of heat flux at different advance injection angle.

Figure 7a shows instantaneous heat flux into each measuring point for motored operation at $1500 \mathrm{rpm}$. It can be seen that maximum of heat flux is achieved simultaneously. The difference of maximum values is explained by diversity of velocity on the cylinder head wall. It can be noted fluctuation during gas exchange stroke. It is caused by active mixing of gas in this stroke.

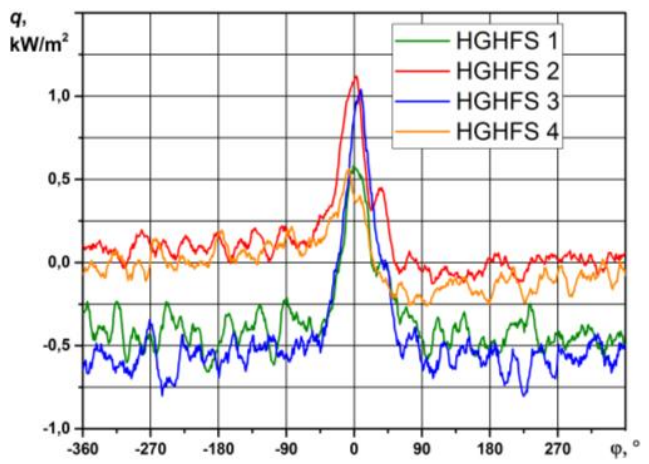

(a)

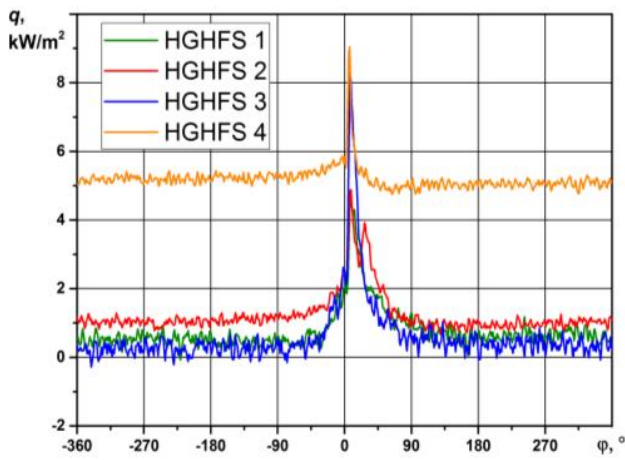

(b)

Figure 7a and Figure 7b. Variation of heat flux into each measuring point for motored and fired operation.

Figure $7 \mathrm{~b}$ shows instantaneous heat flux into each measuring point for fired operation at $1500 \mathrm{rpm}$. It can be seen that maximum of heat flux is achieved simultaneously as in motored operation but peaks are sharper.

\section{Conclusions}

In this work new instrument of measuring heat flux was implemented. Results show stable work of HGHFS for a long period of time. Results corresponds with data from other researchers [21-25]. 
Timing and value of maximum of instantaneous heat flux are tightly linked with advance injection angle. On the regimes with late injection angle it is observed injection process.

Heat flux measurement with the use of HGHFS makes it possible to adequately estimate the level of heat flux. This approach allows to monitor heat flux in the combustion chamber for optimising the working process by varying advance injection angle.

\section{References}

1. S. Broekaert, J. Demuynck, T. De Cuyper, M. De Paepe, and S. Verhelst, Energy, 116(1), 380-391 (2016)

2. J. Torregrosa, A. Broatch, P. Olmeda, J. Salvador-Iborra, and A. Warey, Energy Convers. Manag., 153, 304-312 (2017)

3. A.J. Torregrosa, V. Bermúdez, P. Olmeda, O. Fygueroa, Energy Convers. Manag., 54(1), 57-66 (2012)

4. K. Dejima, O. Nakabeppu, Y. Nakamura, T. Tsuchiya, K. Nagasaka, Int. J. of Engine Res. 00(0), 1-10 (2018)

5. E. Neshat, R. K. Saray, Energy Convers. Manag., 88, 1-14 (2014)

6. O.A. Gerashenko, A.N. Gordov, V.I. Lakh, A.K. Eremina, Temperature measurements: Handbook. Kiev: Naukova dumka, 494 p. (1984)

7. O.A. Gerashenko, Fundamentals of Heatmetry, Kiev: Naukova dumka, 92 p. (1971)

8. S.Z. Sapozhnikov, V.Y. Mitakov, A.V. Mityakov, Fundamentals of gradient Heatmetry, Publishment of Saint-Petersburg polytechnic university, 203 p. (2012)

9. V.V. Osmanov, St. Petersburg State Polytechnic University Journal of Engineering Science and Technology, 4(183), 100-104 (2013)

10. A. Mityakov, V. Mityakov, S. Sapozhnikov, A. Gusakov, A. Bashkatov, V.Seroshtanov, A. Babich, Int. J. of Heat and Mass Transfer, 115, 333-339 (2017)

11. V.Y. Mityakov, S.Z. Sapozhnikov, E.R. Zainullina, A.Y. Babich, O.A. Milto, K.S. Kalmykov. J. Phys.: Conf. Ser. 891(1) 012128 (2017) https://doi.org/10.1088/1742$6596 / 891 / 1 / 012128$

12. V.Y. Mityakov, M.A. Grekov, A.A. Gusakov, S.Z. Sapozhnikov, V.V. Seroshtanov, A.V. Bashkatov, K.S. Kalmykov, (2017). J. Phys.: Conf. Ser. 891(1) (2017). https://doi.org/10.1088/1742-6596/891/1/012095

13. R.Z. Kavtaradze, Theory of piston engines. Special chapters, publ. of Bauman Moscow state university, 720 p. (2008)

14. R.Z. Kavtaradze, Local heat transfer in piston engines, publ. of Bauman Moscow state university, 592 p. (2000)

15. J.M. Desantes, A.J. Torregrosa, A. Broatch, P. Olmeda, Energy, 36(1), 60-69 (2011)

16. P. Salvatore. Master thesis (2015)

17. D.R. Buttsworth, R. Stevens, C. R. Stone, Meas. Science and Tech., 16(7), 14871494 (2005)

18. J. Beck, B. Blackwell, C. R. St. Clair Jr. Inverse heat conduction ill-posed problems, 312 p. (1989)

19. N.A. Ivaschenko, L.R. Neuburg, R.Z. Kavtaradze, I.N. Aliev. Vestn. Mosk. Gos. Tekh. Univ. im. N.E. Baumana, Mashinostr. [Herald of the Bauman Moscow State Tech. Univ., Mech. Eng.], 1, 68-79 (2016)

20. Y. Yamada, M. Emi, H. Ishii, Y. Suzuki, S. Kimura, Y. Enomoto. JSAE Review, 23(4), p. 415-421. (2002) 
21. D.C. Rakopoulos. Fuel, 96, 524-534 (2012)

22. J. Demuynck, M. De Paepe, H. Huisseune, R. Sierens, J. Vancoillie, S. Verhelst, Applied Thermal Eng., 31(6-7), 1220-1228 (2011)

23. C.D. Rakopoulos , K.A. Antonopoulos, D.C. Rakopoulos, E.G. Giakoumis, Applied Thermal Eng. 26, p. 1611-1620 (2006)

24. N. Ivanov, V. Ris, N. Tschur, M. Zasimova, Journal of Physics: Conference Series 745(3) 2016

25. A.A. Gorelov, R.M. Gadel'shin, S.N. Nikitin, Teoriya i Praktika Fizicheskoy Kultury (2014)

26. A.V. Karavan, A.E. Bolotin, Teoriya i Praktika Fizicheskoy Kultury (2015) 